\title{
ENCRUZILHADAS CYBERATLÂNTICAS NAS ROTAS DE ÁFRICA: MÚSICA E DISPUTA PELA MEMÓRIA NA FORMAÇÃO DE ACERVOS DIGITAIS
}

\author{
Renato de Lyra Lemos ${ }^{1}$
}

Resumo: Visto que as tecnologias digitais estão cada vez mais presentes nas nossas atividades diárias e que o acesso à informação através da internet vem ampliando-se gradativamente, muitos dos conteúdos que originalmente foram produzidos de forma analógica estão sendo digitalizados ao redor do globo. $\mathrm{O}$ formato dos museus e dos acervos de pesquisas tradicionais vem sendo sistematicamente substituído nas plataformas digitais, seja através da digitalização desses acervos e sua disponibilização em plataformas na internet, seja através do trabalho de colecionadores sem vínculos institucionais que vem promovendo uma maior democratização do conhecimento. Sendo a internet também um espaço de luta pela memória, a existência de sítios eletrônicos como os blogs permitem uma maior possibilidade de acesso a culturas nãohegemônicas, como é o caso da música produzida no continente africano. Essa pesquisa tem por intuito compreender o processo da formação de arquivos para a digitalização de acervos de música africana e sua disponibilização na internet, problematizando os papéis que a música pode exercer na representação das memórias e culturas desses povos contemporaneamente através das redes na internet.

Palavras-chave: África; música; memória; internet; arquivos digitais.

\section{CYBERATLANTIC CROSSROADS IN THE AFRICAN ROUTES: MUSIC AND THE MEMORY DISPUTE IN THE FORMATION OF DIGITAL ARCHIVES}

\begin{abstract}
As digital technologies are increasingly present in our day-to-day activities and access to information over the Internet has been gradually increasing, many of the content that was originally produced analogically is being scanned around the globe. The format of museums and collections of traditional research has been systematically replaced in digital platforms, either through the digitization of these collections and their availability in platforms on the Internet, or through the work of colecctors without institutional links that has been promoting a greater democratization of the knowledge. As the internet is also a space for struggle for memory, the existence of electronic sites such as blogs allow a greater possibility of access to non-hegemonic cultures, as is the case of music produced on the African continent. This research aims to understand the process of the formation of archives for the digitization of collections of African music and its availability on the Internet, problematizing the roles that music can play in the representation of the memories and cultures of these peoples contemporaneously through the networks in the internet.
\end{abstract}

Keywords: Africa; music, memory, internet, digital archives.

\section{CARREFOURS CYBERATLANTIQUES DANS LES ROUTES DE L'AFRIQUE: MUSIQUE ET LE LITIGE DE LA MEMOIRE DANS LA FORMATION DE COLLECTIONES DIGITALES}

\footnotetext{
${ }^{1}$ Doutorando em Antropologia pela Universidade Federal de Pernambuco (PPGA/UFPE). Pesquisador Associado I do Instituto de Estudos da África da Universidade Federal de Pernambuco (IEAf-UFPE). Mestre em Estudos Étnicos e Africanos pela Universidade Federal da Bahia. Historiador, produtor de eventos culturais, radialista e DJ. E-mail: renatoll@gmail.com
} 
Résumé: Alors que les technologies digitales sont de plus en plus présentes dans nos activités quotidiennes et que l'accès à l'information par internet augmente progressivement, une grande partie du contenu initialement produit de manière analogique est en cours de numérisé dans le monde entier. Le format des musées et des collections de recherche traditionnelle a été systématiquement remplacé sur les plateformes digitales, soit par la numérisation de ces collections et leur disponibilité sur des plateformes sur l'internet, soit par le travail de collectionneurs sans liens institutionnels qui ont favorisé une plus grande démocratisation du savoir. L'internet constituant également un espace de lutte pour la mémoire, l'existence de sites électroniques tels que les blogs permet une plus grande possibilité d'accès à des cultures non hégémoniques, comme c'est le cas de la musique produite sur le continent africain. Cette recherche vise à comprendre le processus de formation des archives pour la numérisation des collections de musique africaine et leur disponibilité sur l'nternet, en interrogeant les rôles que la musique peut jouer dans la représentation des mémoires et des cultures de ces peuples à travers les réseaux de l'internet.

Mots-clés: Afrique; musique; mémoire; internet; archives numériques.

ENCRUZILADAS CYBERATLÁNTICAS EN LAS ROTAS DE ÁFRICA: LA MÚSICA Y LA DISPUTA POR LA MEMORIA EN LA FORMACIÓN DE ACEROS DIGITALES

Resumen: Dado que las tecnologías digitales están cada vez más presentes en nuestras actividades diarias y que el acceso a la información a través de Internet se ha ampliado gradualmente, muchos de los contenidos que originalmente se produjeron de forma analógica se están digitalizando alrededor del globo. El formato de los museos y de los acervos de investigaciones tradicionales viene siendo reemplazado sistemáticamente en las plataformas digitales, ya sea a través de la digitalización de esos acervos y su disponibilidad en plataformas en Internet, ya sea a través del trabajo de coleccionistas sin vínculos institucionales que viene promoviendo una mayor democratización del conocimiento. Siendo la Internet también un espacio de lucha por la memoria, la existencia de sitios electrónicos como los blogs permiten una mayor posibilidad de acceso a culturas no hegemónicas, como es el caso de la música producida en el continente africano. Esta investigación tiene por objeto comprender el proceso de formación de archivos para la digitalización de acervos de música africana y su puesta a disposición en Internet, problematizando los papeles que la música puede ejercer en la representación de las memorias y culturas de esos pueblos contemporáneamente a través de las redes en Internet.

Palabras clave: África; música; memoria; internet; archivos digitales.

A preservação da memória através da oralidade é uma característica importante de diversos grupos étnicos no continente africano. Manter uma memória através da oralidade é reviver aquela memória, fazer com que ela siga viva através da fala, do ato de recontar, o qual pode ser significativamente modificado através de sua repetição. Alguns elementos daquela memória podem ser ressignificados para que ela se mantenha compreensível com o passar de gerações, já que vários dos elementos culturais que estão contidos naquela memória vão se modificando com o passar do tempo. Ou seja, o processo de rememorar torna-se assim conectado diretamente ao processo de criação. 
Quando uma pessoa ou grupo conta uma memória, existem vários olhares contidos ali. Esses olhares vão se condensando com o passar do tempo pela rememoração coletiva e se confundindo. A memória individual torna-se irreconhecivelmente coletiva. Assim, a coletividade acaba por formatar aquela memória, decidindo o que nela deve ser mantido e o que pode ou deve ser esquecido. Assim são constituídas as memórias, de recordações e esquecimentos.

Para diversos povos ocidentais, a relação com a memória é expressivamente diferente dessa perspectiva. A memória se mostra como um espaço de disputa, de demonstração de poder, de superioridade ao invés de superação. A memória é um jogo, com ganhadores e perdedores. Não que na perspectiva africana a memória não seja um ambiente relacionado a conquistas. Porém, a partir dos empreendimentos colonialistas, a memória desses povos tornou-se um item desprezado pelos colonizadores.

Durante o processo do tráfico atlântico de escravizados, afim de que os negros africanos pudessem ser comercializados como produtos do outro lado do mundo, ou seja, objetos sem origem, sem desejos e sem História, eram feitos diversos processos simbólicos para que suas memórias fossem apagadas, a fim de que não se rebelassem no novo mundo. Um desses atos era o de dar voltas na chamada Árvore do Esquecimento, no entreposto de Zomai no porto de Ouidah, atual Benin. Os homens deviam dar nove voltas ao redor da árvore e as mulheres sete, a fim de esquecerem as memórias de sua terra, seus costumes, suas identidades. Assim, ao cruzarem o Atlântico de navio, a eles eram impostos novos nomes e novas práticas culturais, como uma maneira de apagarem as antigas. Porém, esse tipo de imposição de práticas culturais não era feito apenas pelos negros escravizados, mas também aos indivíduos em território africano que também estavam sob o jugo dos colonizadores. Assim, estes também tinham de obedecer às suas leis e costumes.

Aos que eram impostos à educação colonial, tinham de deixar para trás seus costumes e memórias e conservar as memórias dos colonizadores, suas conquistas e suas histórias (Achebe, 1978; 2012). A partir disso, tirando vários bons exemplos de luta e perseverança pelas memórias africanas, as Histórias africanas continuaram sendo escritas pelos ocidentais, ainda dentro de uma perspectiva colonial muito intensa mesmo com o pretenso fim do colonialismo. E muito disso persiste ainda hoje quando se fala de memórias dos povos africanos. Por mais que desde os anos 1960, com as independências, muito tenha sido feito para que os africanos contassem suas próprias 
histórias, o Ocidente ainda tem muita relevância política e poder financeiro para tomar a frente nesses empreendimentos.

Assim, as memórias africanas ainda têm sido demasiadamente mediadas pelo Ocidente. Não que necessariamente aí resida o problema, por mais que as experiências de protagonismo africanas tenham nos deixado fascinados com as possibilidades de construção e percepção de suas próprias memórias, mas a forma como muito tem sido feito são, por vezes, significativamente problemáticas. Assim, pretendo neste artigo problematizar a construção de memórias africanas através dos empreendimentos de colecionadores ocidentais de músicas produzidas no continente africano entre as décadas de 1960 e 1980. Acredito ser muito importante problematizar esses tipos de ações, porém compreendendo também as contribuições que muitos colecionadores têm feito em benefício das memórias musicais da indústria fonográfica no continente africano.

Com o processo contemporâneo de digitalização de discos na internet e, dentro disso, o aumento do interesse pelas músicas produzidas por músicos africanos entre as décadas de 1960 e 1980, alguns especialistas no assunto dizem que essa experiência digital tem retirado as músicas dos contextos em que foram produzidas originalmente, perdendo os seus significados (Novak, 2011; Moist, 2013). Ao serem retiradas dos seus contextos de produção, essas músicas acabam adquirindo novos contextos, em geral com uma perspectiva exotizante, que termina privilegiando uma visão que se aproxima bastante das representações coloniais que eram feitas dessas culturas (Aaltonen, 2016).

Afinal, como já vimos mais acima, retirar os africanos escravizados de seus contextos foi uma ação crucial para o empreendimento colonial, e mesmo esta ação contemporânea não sendo de características necessariamente propositais, acaba de certo modo reforçando uma continuidade do modelo das relações coloniais. Contextos culturais de outros continentes como o asiático e o sul-americano também passaram, em dados momentos, por perspectivas similares, mas o caso africano chama atenção não só pela larga escala de crescimento mercadológico nos últimos anos, como também pela frequente homogeneização de uma ampla variedade de culturas através de um único termo: África.

Assim, porquê ao pretenderem salvaguardar as memórias musicais africanas dos períodos de luta por independência no continente, utilizando-se inclusive das narrativas dos próprios músicos e produtores para reconstituir essas cenas musicais, e ainda mais 
aproveitando-se da internet como um espaço em que essas conexões através de redes de colecionadores têm se tornado possíveis, muitos colecionadores de música ainda acabam reforçando as perspectivas dos discursos coloniais de exotização dessas culturas? E tendo isso em mente, qual a relevância dos espaços de interação digital para que isso ocorra desse modo?

Para além da visão científica prática, ou seja, de abordar a questão africana como um problema a resolver, é importante entender que o campo em questão deve ser visto primeiramente a partir da relação do problema conceitual, ou seja, ao invés de buscar uma solução, devemos procurar entender antes qual o problema com que estamos lidando (Macamo, 2016). Assim, tento lidar aqui com a perspectiva do problema a partir não da representação de África como uma ausência, uma incompletude, como algo não acabado, distante (Mbembe, 2001), pois inclusive esse tipo de perspectiva acaba construindo representações bastante problemáticas (Mudimbe, 2013; Macamo, 2016), mas lidar com o assunto sob a perspectiva de um equívoco do colonialismo ocidental para com ele.

O Ocidente sempre teve uma dificuldade muito grande em tentar compreender o outro, pois suas categorias analíticas nunca conseguiram dar conta de uma amplitude de outras formas de vivências e conhecimentos (Mbembe, 2001). Utilizar a si próprios como paradigmas de comparação acabou fazendo com que os ocidentais caíssem em uma armadilha ardilosa, ainda mais ao estabelecerem os africanos como a alteridade absoluta, diferenciando a civilidade e o conhecimento (Ocidente) do seu contrário (África), ou seja, aquilo que não é (Mbembe, 2017).

Esse profundo equívoco do Ocidente ainda serve como exemplo e mediador das relações com África, motivo pelo qual muitas das representações contemporâneas que se fazem do continente ainda serem tão problemáticas. E essas relações impactam diretamente nos processos de memória, pois ao privilegiar ou manter um tipo de representação que enfatiza a alteridade, e tendo já o Ocidente um histórico de fixar essa alteridade como negativa, acaba impondo às culturas africanas uma imagem a qual se torna muito difícil de desvincular.

Desse modo, ao proporem o "resgate" de determinadas memórias, é importante tentar primeiro compreender que tipos de memórias são essas, quais os contextos em que foram produzidas e em que foram "esquecidas" e qual o propósito de se realizar os seus "resgates". 
Como já enfatizei, a construção de memórias é um processo que lida com escolhas. Ou seja, em um determinado momento, para que alguma memória possa permanecer e ter destaque, outras acabam tendo de ser postas no fundo. A pessoa ou o grupo que faz isso determinam essas questões através da relevância, que mesmo sendo um processo bastante subjetivo, tem os seus motivos para que ocorra assim. Resta saber quando tentamos lidar com os processos de rememoração e esquecimento quais seriam esses motivos, o que faz com que determinada memória permaneça e outra desapareça.

Quando lidamos com música e mercado, várias podem ser as questões envolvidas nesse processo. A relevância daquela música para o público consumidor e para a indústria, através, por exemplo, do viés mercadológico, e as relações sociais que a música simboliza, seja em termos de classe, etnia, religião, questões políticas, etc.. Todos esses fatores, mercadológicos e sociais, podem interferir na manutenção de uma carreira artística, na longevidade de uma canção ou disco e na continuidade de um estilo musical. Ou seja, a manutenção das memórias musicais são bastante complexas e quando entram nessa relação os processos de alteridade fazem com que esse processo se torne ainda mais subjetivo.

Fora todos esses fatores, algo crucial contemporaneamente referente à questão mercadológica no Ocidente são os elementos musicais que conectam as músicas produzidas no continente africano com estilos musicais ocidentais como o Rock, Soul, Funk, Disco, Blues e Jazz, fazendo com que essas sonoridades se tornem mais acessíveis aos ouvintes ocidentais. Por isso, estilos musicais que carregam elementos sonoros relativos às culturas de seus países, mas que os reprocessam através das influências de estilos e de instrumentos ocidentais, acabam tendo uma maior chance de acessarem os mercados ocidentais.

O músico malinense Ali Farka Touré é um exemplo significativo dessa relação. Proveniente de pais pertencentes às etnias Songhay e Fula, ele foi muito influenciado por ritmos do norte do Mali como a Takamba, e tocava inicialmente um instrumento característico desse ritmo, o Ngoni. Posteriormente, ao utilizar o violão e a guitarra ele passou a adaptar o estilo de tocar aquele instrumento, os acordes e os ritmos para esses instrumentos ocidentais. Com a inserção do músico no mercado ocidental, especialmente no final dos anos $1980^{2}$, os críticos sentiram a necessidade de um

\footnotetext{
${ }^{2}$ Período em que os discos do artista passaram a serem lançados no mercado inglês através do selo fonográfico World Circuit Records.
} 
marcador ocidental que pudesse servir como mediador para que os ouvintes pudessem identificar o ritmo sem ouvi-lo. Assim surgiu a alcunha Desert Blues e posteriormente Mali Blues.

Esses marcadores que passaram a designar o som dos artistas serviam para criar uma familiaridade aos ouvintes ocidentais com algo que lhes fosse próximo, no caso o ritmo Blues, ao mesmo tempo em que levava em si um marcador de alteridade, algo que o diferenciasse do Blues, o tornasse singular, que seria aqui a característica dele ser um gênero desenvolvido a partir do "deserto". O próprio uso do termo "deserto" enquanto "unidade" não dá conta da multiplicidade de culturas que existem na região do Saara e seus arredores, algo que as representações ocidentais não têm condições nenhuma de apreender.

Ao elencar assim um termo ocidental para demarcar o gênero, ao mesmo tempo em que delimita uma variedade de outros estilos tocados por Touré sob o termo genérico de deserto, o estilo do artista passa a ter uma representatividade muito maior por um viés ocidental, ao mesmo tempo em que elimina da memória os outros ritmos que formam o som do artista. Ao ouvir os discos de Touré a sonoridade do Blues tornase um elemento aparente. É possível inclusive perceber a própria influência de artistas desse ritmo como John Lee Hooker em seu estilo, além de que a influência (interferência?) de produtores e músicos ocidentais em seus discos fez com que o tom do Blues fosse mais ressaltado, propositalmente, com o intuito de afirmar ali uma origem do ritmo (Meyerson-Knox, 2007).

Touré acabou incorporando ao seu discurso esse elemento da origem do Blues naquela região, e em seu último disco de carreira ${ }^{3}$, acabou adotando para a capa uma foto no estilo típico de um bluesman estadunidense. Através desses tipos de discursos, as memórias do Blues acabaram se misturando com a de outros estilos musicais do norte do continente africano nas rotas entre o Mississipi e Niafunké ${ }^{4}$, e obviamente, mesmo quando discurso representa em África a origem do processo, o referencial cultural que vai se firmar acaba sendo o ocidental, nesse caso o Blues.

E se a imprensa especializada sempre utilizou esse tipo de referencial, os espaços na internet reproduzem largamente esse tipo de informação. Evidente que uma busca minuciosa em uma plataforma de pesquisa online pode proporcionar informações

\footnotetext{
${ }^{3}$ Savane (2006). Ali Farka Touré, The King of the desert 'blues' singers. World Circuit Records.

${ }^{4}$ O Delta do Mississipi nos Estados Unidos é creditado como o local da origem do Blues, e Niafunké é a cidade onde Ali Farka Touré passou toda a sua vida.
} 
mais precisas sobre o estilo musical tocado por Touré, mas a maior parte dos links encontrados acaba reproduzindo o mesmo referencial ocidental ao definirem a música do artista. Esses tipos de situação são bastante corriqueiros quando se trata de músicas produzidas no continente africano, e se multiplicam através da internet.

Acompanhando blogs e fóruns de discussão sobre músicas africanas nos últimos 15 anos, pude perceber o quanto progrediram as informações sobre os artistas e os contextos culturais, bem como o volume de discos disponibilizados na internet. Primeiramente só eram acessíveis discos novos lançados no mercado, algumas coletâneas com temáticas, ritmos e períodos históricos bastante dispersos e controversos e algumas raras reprensagens. Depois foram surgindo mais relançamentos, as compilações foram ficando mais especializadas e foram surgindo discos raros digitalizados por colecionadores. Muitas músicas raras eram disponibilizadas através de mixtapes, inclusive por causa do processo de exclusividade por parte dos dj's. Depois surgiram blogs bastante específicos sobre determinados ritmos, períodos e países.

Nos blogs, quando surgia um disco, muitas vezes não se tinham informações sobre os artistas, às vezes nem o ano em que o disco tinha sido lançado. Porém, nas partes destinadas aos comentários das postagens foram se formando redes de colecionadores, onde cada pessoa que conseguia uma nova informação disponibilizava para o grupo. Assim, inclusive, foram aparecendo alguns parentes e amigos dos artistas, através dos quais foi possível ter contato com os próprios artistas e saber mais informações sobre os discos.

No meio dessa rede novos blogs foram surgindo, e alguns colecionadores acabaram partindo dos blogs para gravadoras, como foi o caso do Analog Africa, Voodoo Funk e Awesome Tapes From Africa. As redes oportunizaram acessar esses discos raros e o contato dos detentores dos direitos autorais para realizar relançamentos. Verdadeiros arquivos online de música surgiram nesse meio, através de blogs especializados em determinados países, ritmos e períodos, fazendo o levantamento dos discos lançados por determinados artistas e gravadoras e tornando esses discos disponíveis através de cópias digitalizadas. As rotas de colecionadores de música cada vez mais cruzavam seus caminhos no continente africano.

É interessante identificar, como já falei, que entre os discos cobiçados por essa rede, acabavam sempre tendo destaque artistas que cruzavam os ritmos musicais de suas localidades com outros estilos ocidentais como o Funk, Rock, Soul, Blues, Jazz e os 
chamados ritmos latinos, como Rumba, Son, Cumbia, Descarga, Guaguanco e Salsa. Ritmos que se encaixavam nesse tipo de padrão, como o Afrobeat, Ethio-Jazz, Makossa, M'balax, Sato, Afrofunk, Highlife, Rumba Congolesa, etc., tinham muito mais chances de serem digitalizados e/ou relançados por estarem mais próximos dos padrões auditivos ocidentais do que outros ritmos como Gnawa, Takamba, Chaabi, etc., que acabam recebendo a categorização de traditional, folk, popular music ou secular music.

Assim como o caso do Desert Blues que citei mais acima, outros estilos musicais passaram pela mesma situação. Praticamente todos os links que acessei até hoje que falam sobre o Ethio-Jazz ${ }^{5}$, denominam o gênero como uma mistura entre Jazz e ritmos etíopes. Esses ritmos são caracterizados sob essas nomenclaturas que coloquei mais acima, porém nunca são definidos enquanto categoria, que tipos de ritmos são esses. Como o Jazz pertence à noção do senso comum, ou seja, mesmo que não saibam exatamente o que é muitas pessoas já ouviram falar ao redor do mundo, avalia-se que ele serve como base classificatória para explanar o gênero, deixando o prefixo Ethio a cargo do imaginário ocidental sobre o que pode ser música advinda da Etiópia.

Evidente que existem sites e blogs especializados que tentam se distanciar dessa mediação ocidental, como no caso da música etíope o blog my passion for ethiopian music ${ }^{6}$, especializado em música do país. Esses tipos de espaços digitais que se pretendem aprofundar em músicas e estilos de determinadas regiões trazem informações muito ricas, pois ao se especializar em determinado assunto esses colecionadores passam a ir além das informações produzidas no ocidente sobre esses sons, buscando muitas vezes informações primárias e fazendo viagens de campo às regiões.

Esses tipos de empreendimentos se tornam verdadeiros arquivos digitais, com grandes quantidades de discos digitalizados e muitas vezes também com vídeos e fotos, além dos textos produzidos pelos colecionadores com informações que em geral não são acessíveis em livros. Por mais que espaços como esses sejam exceções, eles vêm gradualmente aumentando, e mesmo que ainda não sejam tão significativos para as representações das memórias das músicas produzidas no continente africano, por não terem visibilidade expressiva, ainda sim vêm ajudando bastante para modificar os tipos

\footnotetext{
${ }^{5}$ Estilo musical criado pelo pianista e vibrafonista etíope Mulatu Astatke.

${ }^{6} \mathrm{http}$ ://ethio-pain-music.blogspot.com/
} 
de representações que são feitos de África na internet, possibilitando a existência de fontes que fujam dos referenciais clássicos (e um tanto equivocados) sobre o tema.

Para mim, mesmo com o aumento do interesse sobre músicas produzidas a partir do continente africano e a consequente digitalização e disponibilização desses acervos na internet e no mercado fonográfico contemporaneamente, muitos colecionadores e fãs dessas músicas, acabam adotando uma postura de que mesmo com suas consequências devastadoras, a colonização promoveu uma possibilidade desses músicos modernizarem as músicas de suas regiões através das tecnologias, instrumentos e ritmos dos colonizadores, além de ritmos espalhados pela diáspora os quais os colonizadores teriam também possibilitado não só o surgimento como o acesso deles pelos africanos. E a internet, mesmo sendo lida como um espaço "democrático" para a construção de outras memórias, acaba ainda sujeita a um modelo de memória ocidental eleito pelo sistema capitalista vigente, por indivíduos que pelo seu extenso poder através de capital e conexões, controlam também o ciberespaço. Além disso, a ânsia por tornar disponíveis determinados materiais em meios digitais por parte de alguns colecionadores e fãs acaba fazendo com que em alguns momentos eles sejam disponibilizados sem uma explanação do que se trata, desvinculados de suas origens e contextos sociais, e muitas vezes até sem nem mesmo o registro de que artistas são aqueles contidos nas gravações.

As representações de África são resultado de perspectivas um tanto problemáticas e de relações desiguais que têm se perpetuado historicamente (Bargna, 2010). O seu acesso ainda não é democrático, pois não só a internet não é grátis, além de não ser acessível em algumas regiões do globo, como é necessário o uso de equipamentos eletrônicos que ainda não estão devidamente democratizados. Essa desvantagem da acessibilidade ainda é significativa em África (Bargna, 2010), e isso faz com que a disputa por representatividade em espaços digitais ainda continue desigual. $\mathrm{E}$ por mais que os espaços digitais exerçam um papel crucial na conservação das memórias também são campos igualmente significativos na disputa delas (Silva, 2012).

O ritual da árvore do esquecimento pode nos servir como metáfora para entendermos a manutenção dessa relação. As voltas ao redor da árvore compunham apenas o processo inicial do ritual, que tinha continuidade durante todo o processo de travessia pelo Atlântico e se intensificava nos trabalhos forçados da escravização. Ou seja, era uma rota intensa direcionada ao esquecimento. E embora suas memórias não se 
extinguissem necessariamente desse modo, sua força política diminuía através da subjugação de seus corpos e memórias. A tentativa de fazer os giros contrários ao redor da árvore, ou seja, o processo de rememorar suas histórias em busca de força e representatividade ainda encontra muitas dificuldades, pois mesmo a internet sendo um espaço com possibilidades significativas de democratização e construção do conhecimento, ainda passa por um processo de luta desigual. Porém, mesmo com todas essas dificuldades, as memórias acerca de África cada vez mais vão sendo inseridas nos espaços digitais, e aos poucos os indivíduos africanos vão tendo significativa participação nesses processos, promovendo a reedificação e ressignificação dessas memórias e compreendo a necessidade de um uso consciente da internet para avançar nessa luta.

\section{REFERÊNCIAS}

AALTONEN, Lari. Crate-Digging Columbuses and Vinyl Vespuccis. Exoticism in World Music Vinyl Collections. In. MACHART, Regis; DERVIN, Fred; GAO, Minghui. Intercultural Masquerade. New Orientalism, New Occidentalism, Old Exoticism. New York: Higher Education Press, 2016.

ACHEBE, Chinua. An Image of Africa. In. Research in African Literatures, Vol. 9, No. 1. Indiana: Indiana University Press, 1978. pp. 1-15.

ACHEBE, Chinua. A educação de uma criança sob o protetorado britânico: Ensaios. São Paulo: Companhia das Letras, 2012.

BARGNA, Leopoldo Ivan. Africa, scattered in the web and contained in a notebook. In. NAGUELOVA, K.; NJAMI, S. AtWork - Notebook Collection. Milão: Fondazione Lettera 27, 2012.

MACAMO, Elísio. Respostas sem perguntas, ou: porque a África não é um problema por resolver. In. ÉVORA, Iolanda; FRIAS, Sónia. _ in progress: 2. ${ }^{\circ}$ Seminário sobre Ciências Sociais e Desenvolvimento em África. Lisboa: CEsA, 2016.

MACAMO, Elisio. O padrão pérola indiano. In: Facebook. Disponível em: $<$ https://www.facebook.com/permalink.php?story_fbid=2206310122713353\&id=10000003160 1552>. Acesso em: 21 nov. 2018.

MBEMBE, Achille. On the postcolony. Berkley: University of California Press, 2001.

MBEMBE, Achille. Crítica da Razão Negra. Lisboa: Antígona Editores Refractários, 2017.

MEYERSON-KNOX, Saul. African Blues: the Sound and History of a Transatlantic Discourse. Dissertação de Mestrado. University of Cincinnati, 2007.

MOIST, Kevin M.; BANASH, David. Contemporary Collecting - Objects, Practices, and the Fate of Things. Lanham: The Scarecrow Press, 2013. 
MUDIMBE, Valentin-Yves. A invenção de África. Gnose, filosofia e a ordem do conhecimento. Mangualde: Edições Pedago, 2013.

NOVAK, David. The Sublime Frequencies of New Old Media. In: Public Culture 23, no. 3, 2011. p.603-634.

SILVA, Jamile Borges da. Museus on-line: longevidade e conservação digital da memória. In. SANSONE, Livio (Org.). A política do intangível: museus e patrimônios em nova perspectiva. Salvador: Edufba, 2012. 